\title{
ASSAULT INJURY RATES, SOCIAL CAPITAL, AND FEAR OF NEIGHBORHOOD CRIME
}

\author{
Daniel J. Kruger
}

Prevention Research Center of Michigan, University of Michigan

Peter Hutchison

United Way of Genesee County

Matthew G. Monroe, Thomas Reischl, and

Susan Morrel-Samuels

Prevention Research Center of Michigan, University of Michigan

This study develops an explanatory framework for fear of neighborhood crime based on respondents' social context and local rates of assault injuries. Rates of assault injuries within zip codes are based on hospital discharge records. We find that only four variables have a significant unique contribution to fear of crime: respondent's sex, perceptions of neighborhood social capital, and the rates of struck by/against assault injuries for the 10-24 and 50+ age groups. We also find that the perception of neighborhood social capital moderates the impact of assault injury rates on fear of crime; those who perceive a high level of neighborhood social capital exhibit less sensitivity to assault injury rates. We include a map of assault injury rates and fear of crime by ZIP Code and describe the community context related to our results. (C) 2007 Wiley Periodicals, Inc.

\section{INTRODUCTION}

Fear of crime is an important community concern that affects the viability and sustainability of neighborhoods (Hale, 1996; Miethe, 1995). At the individual level, fear of crime and perception of safety in public places is related to health outcomes, independent of the direct relationship between crime and health (Ferraro, 1995). In order

The Speak to Your Health! Community Survey was supported by the Prevention Research Center of Michigan (Centers for Disease Control and Prevention Grant No. U48/CCU515775) and the Genesee County Health Department. We would like to thank the PRC Survey Committee members, Youth Violence Prevention Center Steering Committee members, and all those who participated in the project, for their assistance. Correspondence to: Daniel J. Kruger, School of Public Health, University of Michigan, 1420 Washington Heights, Ann Arbor, MI 48109-2029. E-mail: djk2012@gmail.com 
to address perceptions of physical insecurity, it is necessary to understand the factors that contribute to those perceptions and how they might be modified. Do individuals fear crime based upon a realistic assessment of their risk of assault, or are these perceptions driven by demographic characteristics, neighborhood conditions and social relationships? Does the type of assault injury (firearm, cut and pierce, struck by and against) influence perceptions of crime differentially and does the age of the victim affect the fears of others? This study uses data from a representative community survey and hospital inpatient and outpatient discharge records to determine the extent to which community residents' fear of crime is related to rates of assault injuries in their local area, and whether these fears are mediated by social context.

In the 1940s, Shaw and McKay (1942) argued that crime rates could be explained in the larger context of broad social forces. Before the suburbanization that followed World War II, urban areas in the USA were a mixture of household residences and locally owned shops. These neighborhoods had strong social cohesion and social capital that deterred crime, due to the daily social presence of residents. Neighborhood residents kept crime in check by monitoring those most likely to get into trouble, especially youths (Fukuyama, 1999; Jacobs, 1992). In the 1950s, the urban population began dispersing into newly developed suburban housing tracts, and many urban neighborhoods were demolished and replaced with government housing projects that changed the character of the area (Scott, 1998).

The capacity for social monitoring was diminished as local stores closed and many residents commuted elsewhere to work during the day. This change in social conditions is believed to be responsible for the rise in the crime rate during the 1960s (Fukuyama, 1999). Neighborhood trust and solidarity strongly influences residents' willingness to intervene for the common good (Coleman, 1990; Putnam, 1993). Sampson, Raudenbush, and Earls (1997) have empirically demonstrated that the association between crime and neighborhood conditions of concentrated disadvantage and residential instability is mediated by neighborhood social capital, the mutual trust of neighbors and willingness to help the common good.

The high incidence of crime in some urban neighborhoods may be due to the lack of formal and informal social networks and to social norms concerning labor force participation and educational attainment (Wilson, 1987; Anderson, 1990). The strong association between social capital and crime may also be a product of a feedback loop where declining social capital spurs an increase in crime, which results in greater fear of crime, psychological and physical withdrawal from the community, and the reduction in local businesses and jobs (Kawachi et al., 1999; Skogan, 1991).

Researchers have investigated the relationships between individuals' fear of crime and a variety of individual and societal characteristics since this subject first came to prominence as a social issue in the mid-sixties (Baumer, 1985, Box, Hale \& Andrews, 1988, Hale, 1996). Previous studies suggest that fear of crime contributes to urban decay by causing feelings of isolation and vulnerability that limit people's interactions with their neighbors (Hale, 1996). Individuals may take protective actions, such as moving to another neighborhood or installing security devices which in turn leads to increased social divisions (Miethe, 1995). Fear of crime is also associated with higher levels of stress which may affect the psychological and physical health of those who are most vulnerable (Nasar \& Jones, 1997).

Skogan and Maxfield (1981) propose that differences in fear of crime among individuals and groups can be understood by thinking in terms of three distinct categories: individual-level characteristics (e.g., age, sex) that may lead to differing 
vulnerabilities to victimization; differing environmental cues and conditions such as incivilities and levels of social capital; and knowledge of crime gained either through the media, past victimization, or knowledge of the victimization of others in the community. Extensive literature reviews by Miethe (1995) and Hale (1996) confirm that much of the subsequent research on fear of crime incorporates this model.

\section{INDIVIDUAL LEVEL PREDICTORS OF FEAR OF CRIME}

One of the most consistent findings in the literature is that women report higher levels of fear and perceived risks of victimization than men (Skogan \& Maxfield, 1981; Warr, 1994; LaGrange \& Ferraro, 1992). Some speculated that this finding, coupled with women's generally lower victimization rates indicated that women were overly fearful of victimization (Pain, 2001). Other studies indicate, however, that higher levels of fear among women are more likely rational responses to everyday life. Crimes against women are frequently unreported (Stanko, 1995); women have less control over public and personal space (Pain 1991), and women's fear of crime is informed by a pervasive threat of sexual violence that raises the potential harm of any altercation (Warr 1985).

Next to gender, age is one of the most routinely studied individual-level correlates with fear of crime. Early research in this field indicated that older people had a higher fear of crime (Clemente \& Kleiman, 1976). These findings led some to assert that, among the elderly, fear of crime was a more serious problem than the threat of crime itself (Jaycox, 1978, Clemente and Kleiman, 1976). Other authors however, have found that older people are not, as a whole, more fearful than younger age groups (Ferraro, 1995). Chadee and Ditton (2003) provide an overview of the relationship between age and fear of crime research and conclude that age has a weak inverse relationship with fear of crime (correlations of -.16 for men and -.04 for women).

Residents of communities that have more social ties, good relations between neighbors, and many civic activities appear to have less fear of crime and feelings of insecurity in their neighborhood (Skogan \& Maxfield, 1981). These community characteristics have been explored using several different indicators. One such construct is social capital, as measured by levels of mutual trust among community members and levels of civic engagement reflected in membership in community and civic groups (Coleman, 1990; Putnam, 1993; Kennedy, Kawachi, \& Prothrow-Stith 1995).

Socioeconomic status and education are related to fear of crime. Higher income has repeatedly been found to be associated with greater perceptions of safety (Austin, Furr, \& Spine, 1994; Skogan \& Maxfield, 1981; Parker, 1988), as have higher levels of education (Skogan \& Maxfield, 1981, Covington \& Taylor, 1991; Kanan and Pruitt, 2002). People who reside in areas with high crime rates report commensurately higher levels of fear of crime (Maxfield \& Skogan, 1981; Hatfield \& Bandaranaike, 2001; Chiricos et al., 2000). One study found the assault arrest rate to be the variable with the most explanatory power (Smith \& Torstensson, 1997). Some of studies examining the relationship between crime rates and fear of crime group neighborhoods into 'high' and 'low' crime areas (Ortega \& Myles, 1987; Parker \& Onyekwuluje, 1991; Warr \& Safford, 1983; Thompson et al., 1992, Parker \& Ray, 1990). Other studies use previous victimization of the respondent or someone known by the respondent as a proxy (Baumer, 1985; Covington \& Taylor, 1991, LaGrange et al., 1992). 
Medical records may offer a more comprehensive picture of violent events than those documented in official police reports. For example, Shepherd et al. (1989 and 1993) found that less than $25 \%$ of assault injuries treated in an emergency room or department were ever reported to the police. They note that using hospital data to monitor injury rates has numerous advantages which include an existing data-collection infrastructure, demographic information such as gender and age, and availability at neighborhood, regional, and national levels. The authors also observe that the presence of the case in the emergency room or department implies that an actual injury has occurred rather than the perception that a crime has been committed. Injury records also provide information about the mechanism of injury (firearm, cut and pierce, struck by and against) which is not consistently available in law enforcement data.

Previous research has documented relationships between fear of crime, demographic characteristics, neighborhood conditions, and social ties, yet few studies have examined how fear of crime is related to the risk of assault injuries (Agnew 1985; DeFrances \& Smith, 1998; Skogan, 1987). We seek to determine whether fear of crime is proportional to the risk of assault, especially for one's age group, and identify the mechanisms of assault injuries have the greatest influence on the fear of crime. We also investigate which demographic and community features influence fear of crime independent of assault injury rates, and which may moderate the relationship between local assault injury rates and fear of crime.

\section{METHOD}

\section{Sample}

This study was conducted in a Midwestern American county characterized by an urban center surrounded by more affluent suburban and rural townships. Flint is an industrial city whose population has grown and declined during the 20th century with the manufacturing capacity of the city's largest employer, General Motors. In 1970, GM employed an estimated 80,000 workers at Flint area plants. GM and affiliated industries currently employ around 15,000 area workers. As these manufacturing jobs left the area, so did a significant portion of Flint's population, declining $36.5 \%$ from 196,940 in 1970 to 124,943 in 2000. The city of Flint also has experienced higher unemployment rates than most urban centers in the State of Michigan. Flint was recently ranked the fourth most dangerous city in the United States (Morgan, 2005).

The Prevention Research Center of Michigan's (PRC/MI) Speak to Your Health! Community Survey was designed to monitor and understand community health and community concerns, monitor the impact of PRC/MI and other health initiatives on community health outcomes, and promote change that improves the health of Genesee County communities. Random samples of households were drawn from Genesee County Census Tracts. Census tracts in the city of Flint were over-sampled, twenty residents were obtained for each Census Tract in Flint and ten residents were obtained for each Census Tract outside of Flint. Telephone interviews were conducted from January to April of 2003.The final sample size was 1862 respondents, $68.5 \%$ of respondents were female. The average age of respondents was 48 years (range: 18-100), 65\% of respondents were European American, 27\% of respondents were African American. Ninety percent of respondents had lived in their current residence for at least a year, the mean time of residency was 16 years. 


\section{Measures}

Demographic items used in this analyses include the respondent's age, sex, race (African American or European American, less than 2\% of the sample indicated another race), and years of education completed. Respondents' social and neighborhood context were represented by three constructs: Social support from family and friends, neighborhood social contact, and neighborhood social capital. Social support from family and friends was assessed by three items (Cronbach's alpha $=.506$ ): How often do people in your family help you out? By family we mean anyone you consider family even if they are not blood or marriage related; Would you say your family members are ... (very close to not close at all) in their feelings to each other?; How often do you see, write, or talk on the telephone with family or relatives who do not live with you?

Neighborhood social contact was assessed by the item, "How often do you and other people in this neighborhood visit in each other's homes or on the street? (Never to Often). There are various definitions of neighborhood social capital (see Portes, 1998), and it may not be possible to construct an empirical measure of social capital that covers the full range of the concept (Forbes \& Wainwright, 2001), however the basic components include the extent to which neighbors trust each other and help each other. We assessed social capital with two items (Cronbach's alpha $=.764)$ : People around here are willing to help their neighbors; People in this neighborhood can be trusted (strongly agree to strongly disagree).

Perceptions of neighborhood crime and safety were assessed with a four item scale (Cronbach's alpha $=.831$ ); the items were "How fearful are you about crime in your neighborhood? (Very fearful to Not at all Fearful"), How safe is it to walk around alone in your neighborhood during the daytime?," "How safe is it to walk around alone in your neighborhood after dark?," (both Extremely dangerous to Completely safe), and "Compared to other neighborhoods, the crime rate in my neighborhood is ... (Very High to Very Low).

\section{Genesee County Injury Surveillance System}

For our investigation, external cause of injury code data (E-codes) were collected from hospital billing records from the three major hospital systems in Genesee County, Michigan; Hurley Medical Center, McLaren Regional Medical Center, and Genesys Regional Medical Center (Ivy, Reischl, Morrel-Samuels, 2004). Medical records personnel extracted and compiled the data into Excel files for the Genesee County Health Department. The data sets contained information on those hospital inpatient and outpatient discharges for injuries defined as those hospital discharges with an E code 800-999 on the hospital billing records (See the National Center for Injury Prevention and Control's Recommended Framework of E-code Groupings for Presenting Injury Mortality and Morbidity Data: www.cdc.gov/ncipc/whatsnew/ matrix1.htm). The patient's age and ZIP Code of residence was recorded along with the description of the E-code. The sample consisted of 77,372 injuries. Frequencies of the three most prevalent mechanisms (struck by/against, cut/pierce, and firearm) of intentional injuries were compiled for 21 ZIP Codes for four age groups; 0-9 years, 10-24 years, 25-49 years, and 50 years and older, to generate twelve categories of assault injuries. 
Geographical Information Systems allows the display of assault injury rates and fear of crime in a way that may be intuitive to community residents. We presented maps of assault injury rates and fear of crime to community members and solicited feedback on how the community context could be related to the results.

\section{Data Analysis}

Complete data were available for 1437 survey respondents, there were 415 respondents that were either missing individual level data or lived in a ZIP Code where assault injury rates were not available. Table 1 shows the comparison between respondents included in analyses and those excluded because of missing data. Those excluded from the analyses had significantly less education, social support, and social contact, and significantly more fear of crime. Cohen (1988) outlines small $(d=.20)$, medium $(d=.50)$, and large $(d=.80)$ effect sizes for the behavioral sciences. All significant differences were in the range of small effects. There were no significant differences for age, social capital, proportion African American, or proportion female.

Descriptives and zero-order correlations were computed for all study variables. We used Hierarchical Linear Modeling (Raudenbush \& Bryk, 2002) to examine the association between perceptions of neighborhood crime and safety and factors at the individual and ZIP Code levels. The measures identified above were entered into the model as binary categorical (sex, race) or standardized scale predictors (age, education, social support, social contact, social capital, length of residency, and perceptions of neighborhood crime and safety at the individual level) and the nine categories of assault injuries by type and age group at the ZIP Code level. The initial model contained direct effects of predictors, a second model tested whether individual level predictors moderated the effect of significant ZIP Code level predictors (assault injury rates). Non-significant factors were trimmed from the model to derive the results as presented. We ran an additional analysis for respondents aged $50+$ to determine whether age specific assault injury rates or the magnitude of assault injury rates for youth and young adults (which account for most of assault injuries) was more important in influencing fear of crime.

Table 1. Comparison of Respondents With Complete and Incomplete Data

\begin{tabular}{lcccr}
\hline Variable & $\mathrm{t}$ & d.f. & $\mathrm{p}$ & $\begin{array}{r}\text { Effect Size } \\
(\mathrm{d})\end{array}$ \\
\hline Age & 1.03 & 1,741 & .348 & .06 \\
Education & 2.09 & 1,757 & .036 & -.13 \\
Social support & 2.37 & 1,774 & .018 & -.14 \\
Social contact & 5.568 & 1,844 & $<.001$ & -.32 \\
Social capital & 1.381 & 1,733 & .168 & -.09 \\
Residency & 0.215 & 1,803 & .830 & .00 \\
Fear of crime & 2.316 & 1,753 & .021 & .14 \\
\hline Variable & Chi-Square & d.f. & $\mathrm{p}$ & \\
\hline \% African American & 2.177 & 1 & 0.140 & \\
\% Female & 2.311 & 1 & 0.128 & \\
\hline
\end{tabular}




\section{RESULTS}

Initial analyses indicated that older respondents had significantly less social support from friends and family, but perceived greater neighborhood social capital and had lower fear of crime than younger respondents (see Table 2). Female respondents reported greater social support from friends and family but also had greater fear of crime than male respondents. African American respondents reported lower levels of neighborhood social contact and neighborhood social capital and higher fear of crime than White respondents. Respondents with higher levels of education reported higher levels of neighborhood social contact and neighborhood social capital and lower fear of crime than respondents with less education. Social support from friends and family was directly related to neighborhood social contact. Neighborhood social contact was directly related to neighborhood social capital and inversely related to fear of crime. Neighborhood social capital was also inversely related to fear of crime.

Zip Code rates of the nine categories of intentional assault injuries were highly inter-correlated (see Table 3). Zero-order correlations among the types were all statistically significant, except for five correlations with cut/pierce and firearm assault injuries in the 0-9 year age group, injuries which were rare events.

Several of the individual level variables were correlated with most of the nine categories of intentional assault injuries (see Table 4). Older respondents tended to live in ZIP codes with lower intentional assault injuries across eight of the nine categories. African American respondents tended to live in ZIP codes with higher intentional assault injuries across all of the nine categories. Respondents reporting higher levels of education, higher levels of neighborhood social contact, and higher levels of neighborhood social capital tended to live in ZIP codes with lower intentional assault injuries. Rates of all nine categories of intentional assault injuries were directly related to respondents' fear of crime.

The Hierarchical Linear Model with all individual level variables and ZIP code assault injury rates found that only a few variables made a substantial unique contribution to the variance in fear of crime (see Table 5). The degree of respondents' perceived neighborhood social capital was inversely related to fear of crime, women experienced higher fear of crime than men, and the ZIP Code rate of Struck by/against assault injuries for the 10-24 year and 50+ year age groups were directly related to fear of crime. No other predictor explained a unique portion of the variance in fear of crime. Our results indicated that frequency of social contact with neighbors is directly related to social capital (see Table 2). We also found a direct relationship between household participation in neighborhood activities such as community gardens and crime watches and neighborhood social capital, $r(1681)=.074, p=.002$.

We tested for moderation in individual level variables. Social capital significantly moderated the impact of ZIP Code rate of struck by/against assault injuries for the $50+$ year age group on fear of crime, so that respondents reporting high social capital were not as strongly influenced by the rate of assault injuries in their ZIP Code in their reported fear of crime. No other variables significantly moderated the relationship of assault injury rates and fear of crime. In the HLM model presented in Table 5, the individual level variables (neighborhood social capital and respondent sex) explained 23.2\% of the variance and the ZIP Code level assault injuries explained $10.9 \%$ of the variance in fear of crime. Analytic results from respondents aged $50+$ indicated that the rate of struck by/against assault injuries within the respondents' age group was a stronger predictor of fear of crime than the struck by/against assault injury rate for 


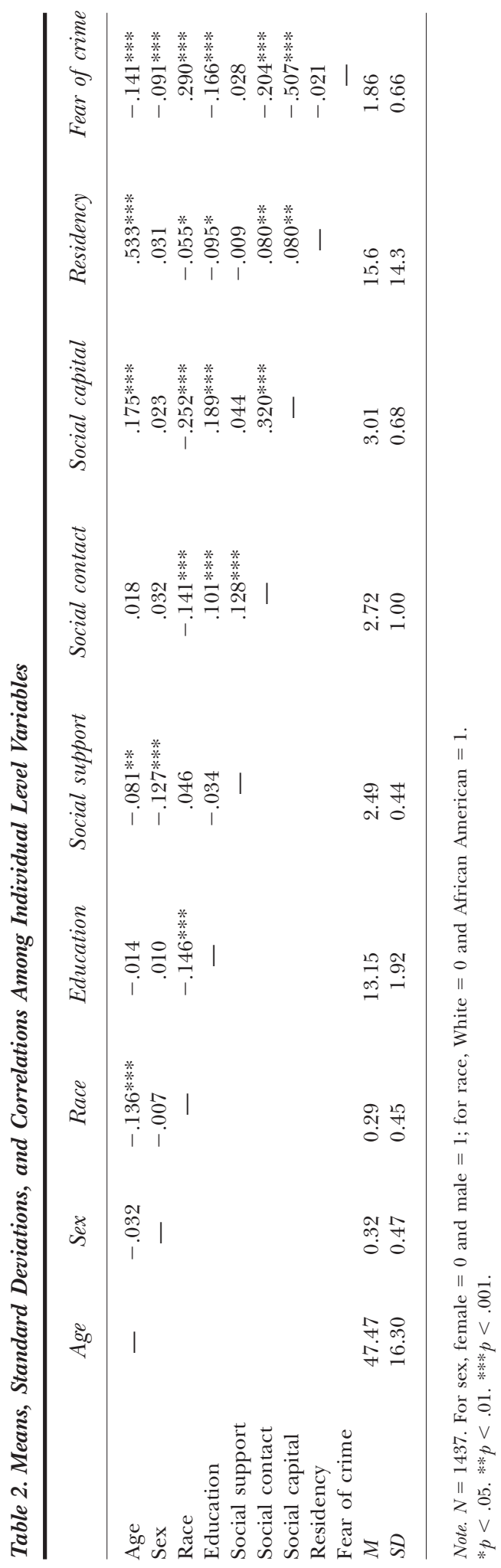




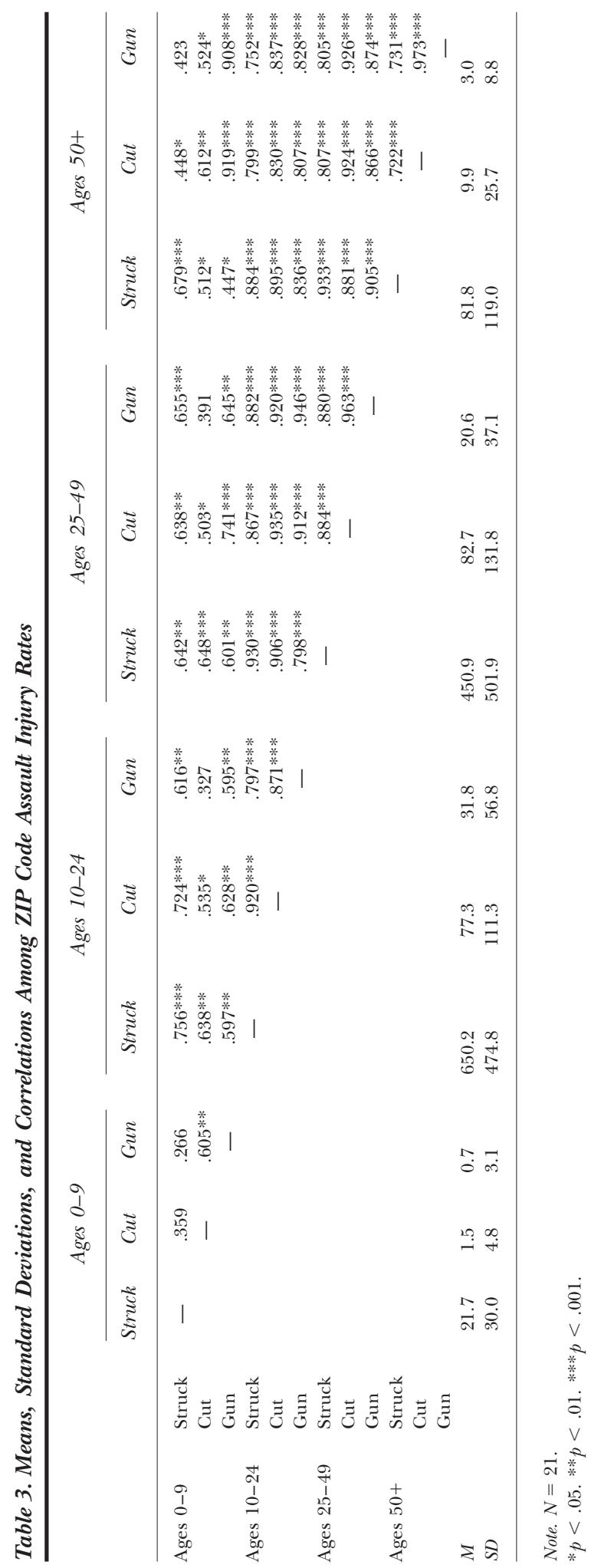




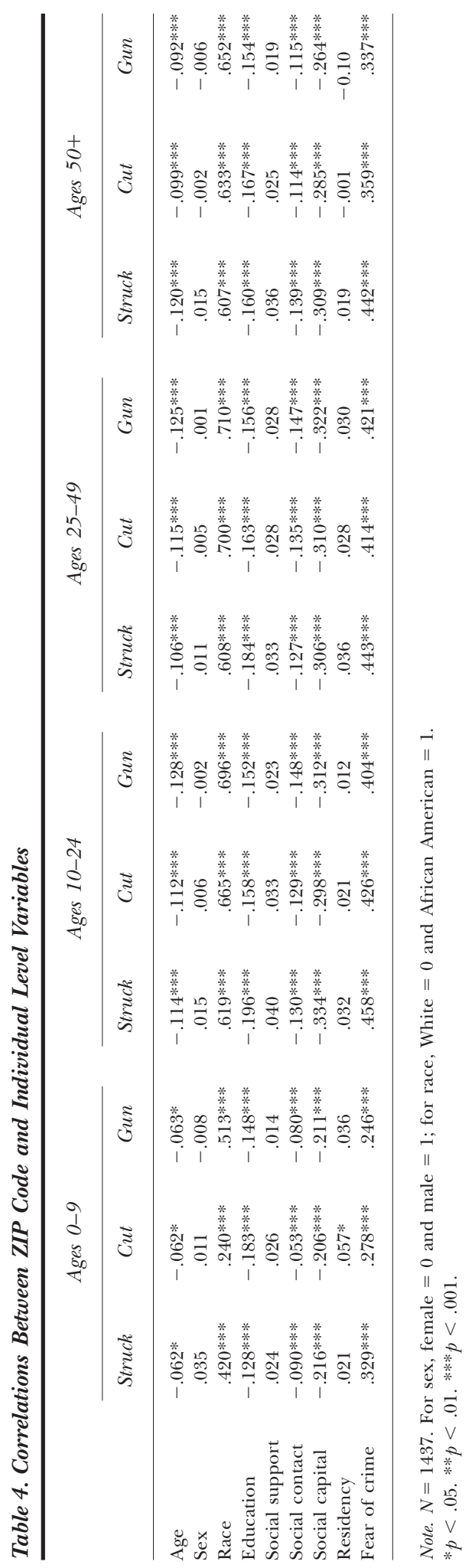


Table 5. Significant Predictors of Fear of Crime in Hierarchical Linear Model

\begin{tabular}{lrrrrr}
\hline Effect & Coefficient & SE & t-ratio & d.f. & p-value \\
\hline Intercept & -0.150801 & 0.029292 & -5.148 & 1431 & $<.001$ \\
1. Sex & -0.185971 & 0.044900 & -4.142 & 1431 & $<.001$ \\
2. Social Capital & -0.347719 & 0.028477 & -12.211 & 1431 & $<.001$ \\
3. Struck 10-24 & 0.180501 & 0.039778 & 4.538 & 1431 & $<.001$ \\
4. Struck 50+ & 0.120957 & 0.037604 & 3.217 & 1431 & $=.002$ \\
5. Struck 50+ $\times$ Social Capital & -0.047704 & 0.018532 & -2.574 & 1431 & $=.010$ \\
\hline
\end{tabular}

youths and young adults (see Table 6). The effects of sex and social capital on fear of crime were consistent for this subsample.

The presentation of maps of assault injury rates and levels of fear of crime elicited a rich description of the community context related to the issues under investigation (see Figure 1). The ZIP Codes in the southwest corner of the map (48436, 48418, 48451) are primarily rural areas with only recent residential development. A relatively large proportion of the residents in this area are older adults who are lifelong residents. The adjacent ZIP code in the southern tip of the county with slightly higher fear of crime (48430) contains the city of Fenton.

ZIP code 48429 has a moderate assault injury rate and a relatively high fear of crime. There is a large mobile home park located in this small zip code, which has a reputation as being a high crime area. The ZIP code areas in the center of the map are in or overlap the city of Flint. The area in the southern end of Flint is primarily comprised of blue collar, white automotive factory workers from the American South, Arkansas and Missouri. These individuals may be long term residents, however many plan to return to their properties in the South when their current employment comes to an end. This transience could contribute to lower psychological investment in the community and relatively higher fear of crime. The south side of Flint has historically more stable neighborhoods than the north side, although the presence of absentee landlords is increasing. The south side of Flint is predominantly Caucasian; the north side is predominantly African-American. The two ZIP Codes in the northwest and north central sections of Flint $(48504,48505)$ are typically depressed in studies of quality of life issues. There are high concentrations of rental properties and abandoned housing in these zip codes, as well as few commercial services.

ZIP code 48506, across the Flint River, is similar in socio-demographic composition, although it differs in ethnic composition. This area contains the largest Hispanic population in the County and is home to the largest gangs in the County. The area

Table 6. Comparison of Effects for Respondents 50 and Older

\begin{tabular}{|c|c|c|c|c|c|}
\hline Effect & Coefficient & $S E$ & t ratio & d.f. & $\mathrm{p}$ value \\
\hline Intercept & -0.178276 & 0.043381 & -4.110 & 18 & $<.001$ \\
\hline 1. Sex & -0.267662 & 0.066586 & -4.020 & 639 & $<.001$ \\
\hline 2. Social Capital & -0.434914 & 0.035951 & -12.098 & 639 & $<.001$ \\
\hline 3. Struck $10-24$ & 0.122119 & 0.069059 & 1.768 & 18 & $=.093$ \\
\hline 4. Struck $50+$ & 0.146565 & 0.066342 & 2.209 & 18 & $=.040$ \\
\hline
\end{tabular}




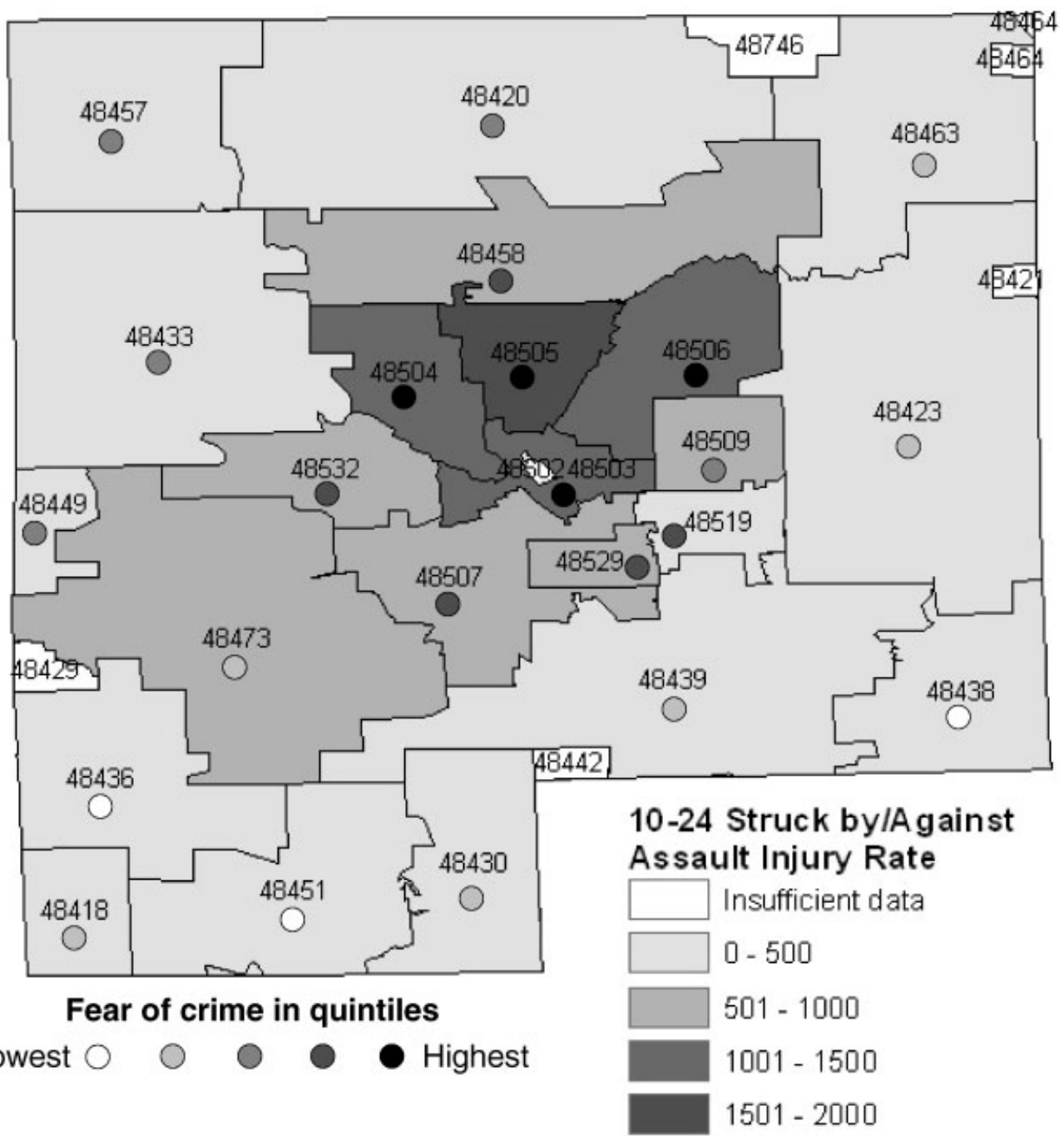

Figure 1. Rate of struck by/against 0-24 year assault injuries and average fear of crime by ZIP Code.

also contains considerable non-residential areas such as factories, salvage yards, and the railroad. North of these three areas is the city of Mt. Morris and Mt. Morris and Genesee Townships (48458). The two townships are predominately African American and have some similarities to the adjacent areas in Flint, although this area underwent a more recent transition from Caucasian to African-American in the last 30-40 years. The three police jurisdictions in this area may create a much greater presence of law enforcement than in the areas to the immediate south.

The far eastern and western portions of the county contain the middle and uppermiddle class communities of Davison (48423) and Flushing (48433), respectively. The northernmost areas of the county are predominately rural $(48420,48463)$. There appears to be relatively high fear of crime in the northwestern corner of the county (48457). This is an area that has experienced a rising proportion of migrant farm workers and related gang activity. The area is also adjacent to Saginaw County, which 
has also experienced an increase in gang activity. In the northernmost area of the county, some of the residents are closer to the hospitals in the Saginaw area than those in Genesee County, and this may affect the reported rate of assault injuries in our data.

\section{DISCUSSION}

We found that fear of crime is indeed proportional to the risk of assault injury, and that the risk of assault injury in one's age group is particularly important for older respondents. The most frequent form of assault injury, struck by and against, was the strongest predictor of fear of crime amongst the various types of assault injuries. Once this form of assault injury was accounted for, less frequent but more adverse forms of assault did not account for variance in respondents' fear of crime. Youths and young adults ages 10-24 had higher rates of assault injuries than the other two age groups, and struck by/against assaults were more common than cut/pierce and firearms assaults. Most of the age group and assault type combinations were far less frequent, for example only three of the 21 ZIP codes had any intentional firearms injuries for ages 50 and above.

Over one third of the variance in neighborhood residents' fear of crime and perceptions of neighborhood safety was accounted for by only four predictors; sex, perceptions of neighborhood social capital, and the ZIP Code rate of struck by/against assault injuries for youth ages 10 to 24 and adults aged $50+$. Once these predictors were in the model, other demographic variables, perceptions of neighborhood social conditions, and other types of assault injuries did not account for a significant unique proportion of the variance.

Our results demonstrate the importance of neighborhood social capital to neighborhood residents. Perceptions of social capital had both a direct relationship to fear of crime and perceptions of neighborhood safety, and also moderated the impact of struck by/against youth assault injuries. Although we cannot confirm causality with our correlational model, it has been previously suggested that social capital and crime have a reciprocal relationship (Kawachi et al., 1999; Skogan, 1991). Flint's residential neighborhoods are composed primarily of single family homes, with a small proportion of duplexes and multifamily units. There are few high-rise apartment or condominium buildings, compared to other cities of similar size.

These neighborhood characteristics may encourage efforts to enhance neighborhood interaction. Frequency of contact with neighbors was related to social capital and post-hoc analyses indicated that respondents whose household members participated in neighborhood activities such as community gardens and crime watches perceived higher neighborhood social capital. Promoting such neighborhood activities may both lead to decreased rates of crime and ameliorate the psychological impact of local crime rates.

Women experienced greater fear of crime and felt less safe in their neighborhood, consistent with our expectations and the results of previous research. Taken together, individual level predictors accounted for over $23 \%$ of the variance in fear of crime and perceptions of neighborhood safety, which is quite substantial in comparison to other similar studies. Other demographic predictors such as age, race, and educational attainment did not significantly account for additional variance, unlike in previous studies. These factors covary with the predictors used in our model and were controlled for in the analyses. Demographic "effects" beg the question of the mechanism 
which is responsible for the relationship, so it is possible that other studies would also partial out demographic characteristics if factors more proximal to the predicted variable were included.

An additional $10.9 \%$ of the unique variance in fear of crime and perceptions of neighborhood safety was accounted for by the rate of struck by/against youth/young adult and age $50+$ assault injuries. The strength of this effect is quite remarkable, especially considering the heterogeneity of ZIP Codes. Community researchers have cited the heterogeneity of census tracts as presenting problems for determining neighborhood effects (e.g., Wiesenfeld, 1996), and ZIP Codes are typically larger areas that are even more heterogeneous than census tracts. It is likely that the relationship found between local assault injury rates and fear of crime would be even stronger if more precise geographical indicators were available for the injury data.

\section{CONGLUSIONS}

This study reaffirms the importance of neighborhood context in understanding community residents' fear of neighborhood crime and perceptions of neighborhood safety. Our results suggest that community interventions promoting communication and cooperation among neighbors, and thus enhancing social capital, may be effective in reducing fear of crime. Greater social capital may also promote a stronger sense of community that could reduce actual crime rates through social vigilance. Geographic mapping of injury rates can assist communities in understanding relative neighborhood conditions and focusing interventions on the areas of greatest need.

\section{REFERENCES}

Agnew, R.S. (1985). Neutralizing the impact of crime. Criminal Justice and Behavior, 12(2), 221-239.

Austin, M.D., Furr, L.A., \& Spine, M. (2002). The effects of neighborhood conditions on perceptions of safety. Journal of Criminal Justice, 30, 417-427.

Baumer, T.L. (1985). Testing a general model of fear of crime: Data from a national sample. Journal of Research in Crime and Delinquency, 22(3), 239-255.

Box, S., Hale, C., \& Andrews, G. (1988). Explaining fear of crime. British Journal of Criminology, 28(3), 340-356.

Chadee, D., \& Ditton, J. (2003). Are older people most afraid of crime? Revisiting Ferraro and LaGrange in Trinidad. British Journal of Criminology, 43(2), 417-433.

Chiricos, T., Padgett, K., \& Gertz, M. (2000). Fear, TV news, and the reality of crime. Criminology, 38(3), 755-785.

Clemente, F., \& Kleiman, M.B. (1976). Fear of crime among the aged. The Gerontologist, 16(3), 207-210.

Cohen, J. (1988). Statistical power analysis for the behavioral sciences (2nd ed.). New York: Academic Press.

Coleman, J.S. (1990). Foundations of social theory. Cambridge, MA: Harvard University Press.

Covington, J., \& Taylor, R.B. (1991). Fear of crime in urban residential neighborhoods: Implications of between and within neighborhood sources for current models. The Sociological Quarterly, 32(2), 231-249.

DeFrances, C.J., \& Smith, S.K. (1998) Perceptions of neighborhood crime, 1995. U.S. Dept. of Justice, Office of Justice Programs, Bureau of Justice Statistics. 
Ferraro, K.F. (1995) Fear of crime: Interpreting victimization risk. Albany, NY: State University of New York Press.

Forbes, A., \& Wainwright, S.P. (2001). On the methodological, theoretical and philosophical context of health inequalities research: A critique. Social Science \& Medicine, 53, 801-816.

Fukuyama, F. (1999). The great disruption. Human nature and the reconstitution of social order. London: Profile Books.

Hale, C. (1996). Fear of crime: A review of the literature. International Review of Victimology, 4(2), $79-150$

Ivy, W., Reischl, T., \& Morrel-Samuels, S. (2004). Adolescent assault injury profile of Genesee County, MI 2002. Youth Violence Prevention Center, University of Michigan.

Jacobs, J. (1992). The death and life of great American cities. New York: Vintage Books.

Jaycox, V.H. (1978). The elderly's fear of crime: Rational or irrational? Victimology, 3, $329-334$.

Kanan, J.W., \& Pruitt, M.V. (2002). Modeling fear of crime and perceived victimization risk: The (in) significance of neighborhood integration. Sociological Inquiry, 72(4), 527-548.

Kennedy, B.P., Kawachi, I, \& Prothrow-Stith, D. (1998). Social capital, income inequality, and firearm violent crime. Social Science \& Medicine, 47(1), 7-17.

LaGrange, R.L., Ferraro, K.F., \& Supancic, M. (1992). Perceived risk and fear of crime: Role of social and physical incivilities. Journal of Research in Crime \& Delinquency, 29(3), 311-334.

Lindstrom, M., Merlo, J., \& Ostergren, P.O. (2003). Social capital and sense of insecurity in the neighbourhood: A population-based multilevel analysis in Malmo, Sweden. Social Science and Medicine, 56(5), 1111-1120.

Miethe, T.D. (1995). Fear and withdrawal from urban life. Annals of the American Academy of Political and Social Science, 539, 14-27.

Morgan, S. (2005). City crime rankings (12th ed.). Lawrence, KS: Morgan Quinto Press.

Nasar, J.L., \& Jones, K.M. (1997). Landscapes of fear and stress. Environment and Behavior, 29(3), 291-323.

Pain, R. (1991). Space, sexual violence and social control: Integrating geographical and feminist analyses of women's fear of crime. Progress in Human Geography, 15, 415-431.

Pain, R. (2001). Gender, race, age and fear in the city. Urban Studies, 38(5-6), 899-913.

Parker, K.D. (1988). Black-White differences in perceptions of fear of crime. Journal of Social Psychology, 128(4), 487-494.

Phinney, J. (1992). The Multigroup Ethnic Identity Measure: A new scale for use with adolescents and young adults from diverse groups. Journal of Adolescent Research, 7, 156-176.

Portes, A. (1998). Social capital: Its origins and applications in modern sociology. Annual Review of Sociology, 24, 1-24.

Putnam, R.D. (1993). Making democracy work. Civic traditions in modern Italy. Princeton: Princeton University Press.

Putnam, R.D. (2000). Bowling alone. The collapse and revival of American community. New York, London: Simon and Schuster.

Raudenbush, S.W., \& Bryk, A.S. (2002). Hierarchical linear models: Applications and data analysis methods. Thousand Oaks: Sage Publications.

Scott, J.C. (1998). Seeing like a state: How certain schemes to improve the human conditions have failed. New Haven, CT: Yale University Press.

Shaw, C., \& McKay, H. (1942). Juvenile delinquency and urban areas. Chicago: University of Chicago Press.

Shepherd, J., Shapland, M., \& Scully, C. (1989). Recording by the police of violent offences; an accident and emergency department perspective. Medicine, Science and the Law, 29(3), $251-257$. 
Shepherd, J.P., Ali, M.A., Hughes, A.O., \& Levers, B.G.H. (1993). Trends in urban violence: A comparison of accident department and police records. Journal of the Royal Society of Medicine, 86, 87-92.

Skogan, W.G., \& Maxfield, M.G. (1981). Coping with crime: Individual and neighborhood reactions. Beverly Hills, CA: Sage Publications.

Smith, W.R., \& Torstensson, M. (1997). Gender differences in risk perception and neutralizing fear of crime. British Journal of Criminology, 37(4), 608-634.

Stanko, E.A. (1995). Women, crime, and fear. Annals of the American Academy of Political and Social Science, 539, 46-58.

Warr, M. (1985). Fear of rape among urban women. Social Problems, 33(3), 238-250.

Warr, M. (1994). Public perceptions and reactions to violent offending and victimization. In A.J. Reiss, Jr., \& J.A. Roth (Eds.), Understanding and preventing violence: Vol. 4. Consequences and control (pp. 1-66). Washington, DC: National Academy Press.

Wiesenfeld, E. (1996). The concept of "we": A community social psychology myth? Journal of Community Psychology, 24, 337-345. 